\title{
Selected Topics on Business Informatics Research: Introduction to Issue 21 of CSIMQ
}

\author{
Raimundas Matulevičius ${ }^{1 \star}$ and Václav $\breve{R e p a}^{2}$ \\ ${ }^{1}$ Institute of Computer Science, University of Tartu, Tartu, Estonia \\ ${ }^{2}$ University of Economics Prague, Prague, Czech Republic \\ rmadut.ee, repa@vse.cz
}

Business informatics research focuses on the fields of business informatics and information systems and bridges business applications and information systems engineering to facilitates the communication between scientists and practitioners. This issue of the journal on Complex Systems Informatics and Modeling Quarterly contains publications that present extended papers from the workshops of the 18th International conference on Perspectives in Business Informatics Research (BIR 2019), organised in Katowice, Poland, 23-25 September, 2019. The theme of the conference was Responsibilities of Digitalisation - Responsible Designing and Shaping the Future of Technology for Digital Preservation, Global Data Storage and Cost-Effective Management. The BIR 2019 workshops captured important and novel topics on security analytics, managed complexity, and information logistics and digital transformation. In this issue we also include one paper from the main BIR conference.

Contribution by Saddiqa et al. shows how to use the enterprise architecture oriented requirements engineering approach for open data usage as an educational resource. A case is considered with respect to the Danish public schools and reported in the article "Enterprise Architecture Oriented Requirements Engineering for the Design of a School Friendly Open Data Web Interface." The article reports that the open data potentially can be used as an educational resource, it supports both the teachers and the students as they can get in touch with the real problems and consider the real life solutions.

In the article "Conceptual modeling Education as a "Design Problem"," Buchmann et al. focus on conceptual education issues. The underlying statement is that conceptual modeling languages should primality be used as the tools to capture emerging problems. This is supported by the open models laboratory (OMiLAB), which suggests the digital ecosystem for explaining the model value using the open community experience.

Contribution by Lantow et al., entitled "Method and Notation Application for Case Model Creation in the Social Sector," proposes a method for the adaptive case management. The authors are proposing extensions to the Case Management Model and Notation" (CMMN) and show its

\footnotetext{
^ Corresponding author

(c) 2019 Raimundas Matulevičius et al. This is an open access article licensed under the Creative Commons Attribution License (http://creativecommons.org/licenses/by/4.0).

Reference: R. Matulevičius and V. Řepa, "Selected Topics on Business Informatics Research: Introduction to Issue 21 of CSIMQ," Complex Systems Informatics and Modeling Quarterly, CSIMQ, no. 21, pp. I-II, 2019. Available: https://doi.org/10.7250/csimq.2019-21.00

Additional information. Author ORCID iD: R. Matulevičius - https://orcid.org/0000-0002-1829-4794 and V. Řepa https://orcid.org/0000-0001-9113-3447. PII S225599221900120X. Received: 23 December 2019. Available online: 31 December 2019.
} 
feasibility and applicability in the social care sector. The study also illustrates the existing workflow to enable the case management activities.

In the article "Evaluation of Adblock Software Usage Development," Sołtysik-Piorunkiewicz et al. study the social and technical factors that influence the usage of the adblock software. The main results show that the adblock software is used because of the frequently displaying advertisements, because of slow loads of the Websites, and because users need to protect their computers against malware. This also includes the necessity to manage users' privacy and secure their social communications.

The CSIMQ editorial team would like to thank all the authors, who submitted their articles to this issue. We also thank to all reviewers for providing valuable comments and improvement proposals for the submitted articles. 